\title{
A Shell Model for the Filament Structure of Bi-2223 Conductors
}

\author{
T. G. Holesinger, J. A. Kennison, S. Liao, Y. Yuan, J. Jiang, X. Y. Cai, E. E. Hellstrom, D. C. Larbalestier, \\ R. M. Baurceanu, V. A. Maroni, and Y. Huang
}

\begin{abstract}
Phase development during the first few minutes of heat treatment of first generation $(\mathrm{Bi}, \mathrm{Pb})_{2} \mathrm{Sr}_{2} \mathrm{Ca}_{2} \mathrm{Cu}_{3} \mathrm{O}_{\mathrm{y}}$ (Bi-2223) multifilamentary wires determines to a large extent the overall microstructure, the efficiency of primary phase development, competing secondary phase development, texture evolution, and grain-to-grain connectivity. It is shown that the filament structure of these wires can be described in terms of a shell model. The shell next to the silver sheath is comprised of well-formed Bi-2223 colonies grapho-epitaxially aligned to the silver sheath and only a few grains (average one colony) thick. Inside this shell is a less well-aligned, less phase pure, more porous Bi-2223 structure through which current is carried in a nonuniform manner as shown by MOI.
\end{abstract}

Index Terms-Bi-2223, bismuth compounds, high-temperature superconductor, microscopy, processing.

\section{INTRODUCTION}

$\mathbf{M}$ ULTIFILAMENTARY

$(\mathrm{Bi}, \mathrm{Pb})_{2} \mathrm{Sr}_{2} \mathrm{Ca}_{2} \mathrm{Cu}_{3} \mathrm{O}_{\mathrm{y}}$ (Bi-2223) tapes are of interest for the development of superconducting motors, generators, transmission lines, and electro-magnets. Production tapes are technically capable of satisfying application requirements and robust with respect to the environmental extremes encountered during incorporation into and operation of practical devices [1]. Critical current densities $\left(\mathrm{J}_{\mathrm{c}}\right.$ 's) have reached $69.6 \mathrm{kA} / \mathrm{cm}^{2}$ (self-field, $77 \mathrm{~K}$ ) in experimental Ag-sheathed Bi-2223 tapes [2]. However, significantly higher $\mathrm{J}_{\mathrm{c}}$ values approaching $300 \mathrm{kA} / \mathrm{cm}^{2}$ have been observed for parts of these tapes by current reconstructions of magneto-optical images [3]. $\mathrm{J}_{\mathrm{c}}$ values greater than $1000 \mathrm{kA} / \mathrm{cm}^{2}$ have been observed in thin films [4]. Multiple studies have been carried out to identify and quantify current limiting mechanisms such as cracks, porosity, and $(\mathrm{Bi}, \mathrm{Pb})_{2} \mathrm{Sr}_{2} \mathrm{CaCu}_{2} \mathrm{O}_{\mathrm{y}}(\mathrm{Bi}-2212)$ intergrowths [3], [5]-[14]. Based on recent microstructural work and previous reports, a model was constructed for describing the overall structure of

Manuscript received October 4, 2004. This work was supported in part under the auspices of the United States Department of Energy, Office of Electric Transmission and Distribution, as part of a DOE program to develop electric power technology under Contract W-7405-ENG-36.

T. G. Holesinger and J. A. Kennison are with Los Alamos National Laboratory, Los Alamos, NM 87545 USA (e-mail: holesinger@lanl.gov).

S. Liao, Y. Yuan, J. Jiang, X. Y. Cai, E. E. Hellstrom, and D. C. Larbalestier are with the University of Wisconsin, Madison, WI 77005 USA (e-mail: larbalestier@engr.wisc.edu).

R. M. Baurceanu and V. A. Maroni are with Argonne National Laboratory, Argonne, IL 60439 (e-mail: maroni@cmt.anl.gov).

Y. Huang is with American Superconductor, Westborough MA (e-mail: yhuang@amsuper.com).

Digital Object Identifier 10.1109/TASC.2005.847509 the filaments and their formation in Bi-2223 monocore and multifilamentary tapes.

\section{EXPERIMENTAL}

Green (i.e. unreacted) and fully-processed, high $\mathrm{J}_{\mathrm{C}} \mathrm{Bi}-2223$ multifilamentary tapes were obtained from American Superconductor. The starting composition of the $\mathrm{Bi}-2223$ powder used in the tapes was $\mathrm{Bi}_{1.7} \mathrm{~Pb}_{0.3} \mathrm{Sr}_{1.9} \mathrm{Ca}_{2.0} \mathrm{Cu}_{3.0} \mathrm{O}_{\mathrm{y}}$. Several of the green tapes were processed in a vertical furnace and quenched in an oil bath after $1,10,100,150$, and 300 minutes at $827^{\circ} \mathrm{C}$ in $8 \%$ $\mathrm{O}_{2} / \mathrm{N}_{2}$. High- $\mathrm{J}_{\mathrm{c}}$, monocore and multifilamentary tapes were obtained from the University of Wisconsin where over-pressure processing was incorporated into the heat treatments [2].

Tapes were examined in scanning and transmission electron microscopes (SEM and TEM). Quantitative compositional analysis was performed by energy dispersive spectrometry (EDS) in the TEM using as standards a glass of composition $\mathrm{Bi}_{2.15} \mathrm{~Pb}_{0.0} \mathrm{Sr}_{1.94} \mathrm{Ca}_{0.91} \mathrm{Cu}_{2.01} \mathrm{O}_{\mathrm{y}}$ and a $\mathrm{Ca}_{2} \mathrm{PbO}_{4}$ pellet prepared by solid state synthesis. Further details of the TEM specimen preparation and quantification method can be found in previous work [6], [8]. Cross section area measurements and standard transport measurements in self and applied magnetic fields were used to determine the $\mathrm{J}_{\mathrm{c}}$ values at $77 \mathrm{~K}$ with an electric-field criterion of $1 \mu \mathrm{V} / \mathrm{cm}$. DC magnetization curves were taken in a SQUID magnetometer as a function of temperature using a standard zero-field-cooled procedure and a background field of $5 \mathrm{G}$ applied along the long axis of the tapes [11]. Magneto optical images (MOI) were collected and current reconstruction maps were produced for some of the tapes [3].

\section{RESULTS}

\section{A. Filament Microstructure of Fully Processed Tape}

TEM studies show that the structure of the filaments can be described in terms of a shell and core contained within the silver sheath. The shell consists of a few grains that share a common c-axis (colony) and are grapho-epitaxially aligned (c-axis perpendicular) to the silver/Bi-2223 interface. In almost all cases, the first grain next to the silver sheath is devoid of $\mathrm{Bi}-2212$ intergrowths. The remaining grains in the Bi-2223 shell colony may or may not contain intergrowths. The shell region contains few secondary phases. Disruptions in the shell continuity are due to the defects in the BSCCO/silver sheath interface. An example is shown in Fig. 1, where a discontinuity in the silver sheath has resulted in the formation of several high-angle colony boundaries. These latter boundaries have as one side the basal plane of one of the Bi-2223 colonies. 


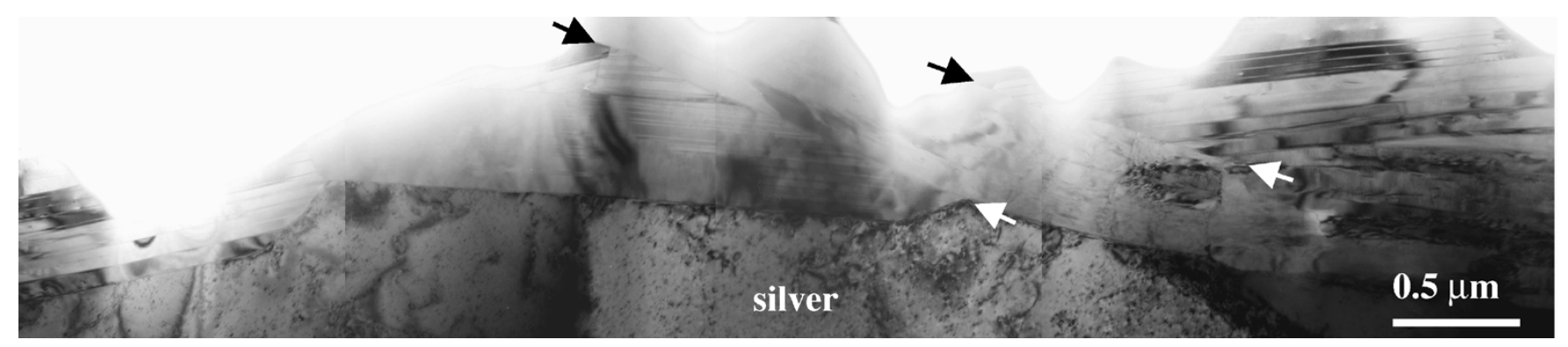

Fig. 1. TEM cross-section of the Bi-2223 colony structure around a discontinuity in the silver sheath. The black and white arrows indicate grain boundaries between colonies where one side is formed by the basal plane of one of the colonies.
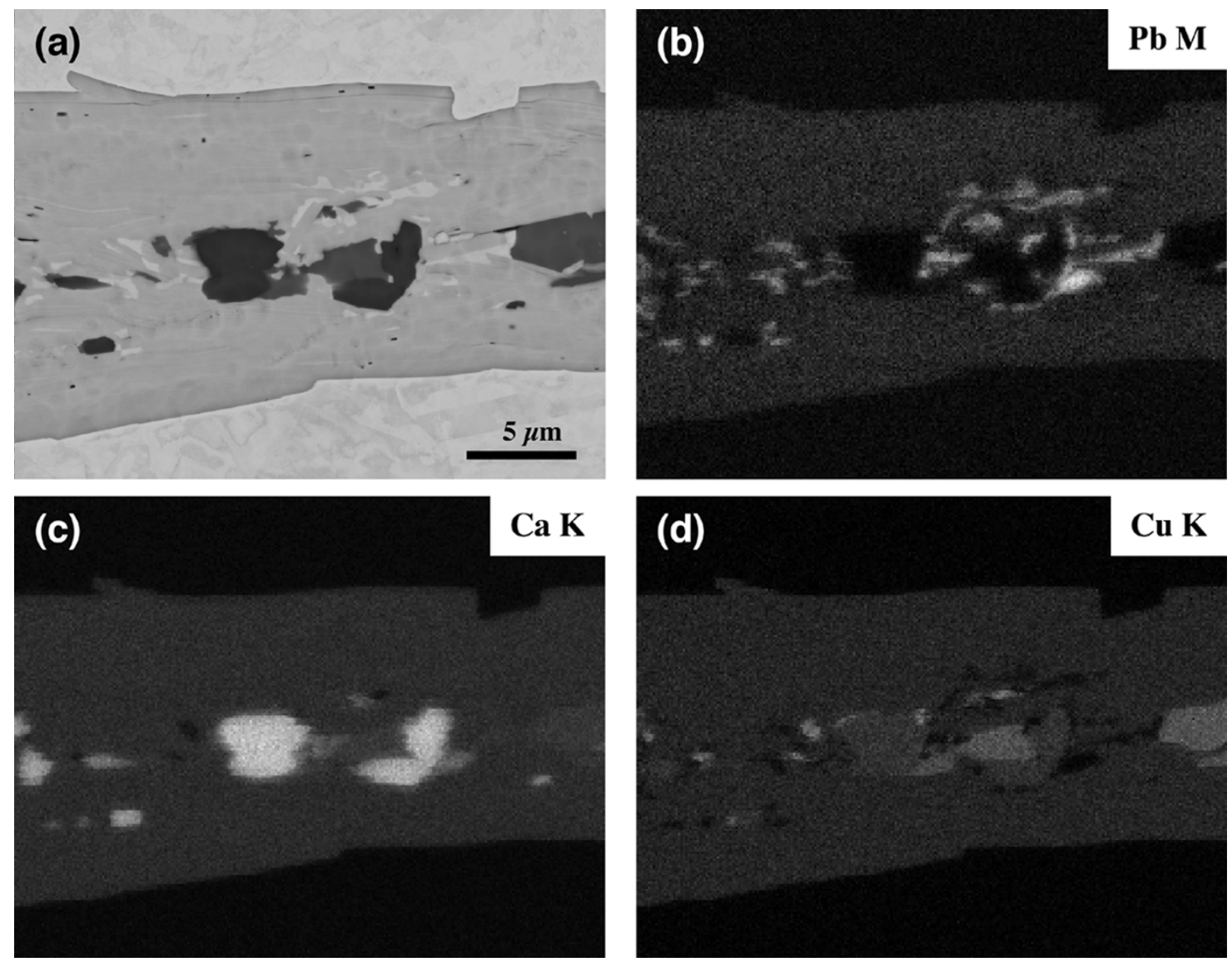

Fig. 2. SEM images and elemental EDS maps of a filament in a fully reacted Bi-2223 tape. The backscattered electron image of (a) shows a dense structure with most of the secondary phase confined to the filament center as indicated by the $\mathrm{Pb}, \mathrm{Ca}$, and $\mathrm{Cu}$ maps of (b), (c), and (d).

The interior region consists of $\mathrm{Bi}-2223$ colonies that are not as well-aligned to the silver sheath interface. The core region contains nearly all the porosity, secondary phases, and intergrowth structures as illustrated by Fig. 2. The sample shown in Fig. 2 was given a final, overpressure processing step which resulted in a $\mathrm{J}_{\mathrm{c}}$ and $\mathrm{I}_{\mathrm{C}}(77 \mathrm{~K}, 0.1 \mathrm{~T})$ of $26.9 \mathrm{kA} / \mathrm{cm}^{2}$ and 73.2 A, respectively. The secondary phases in the center of the filament were identified as the Ca-rich $(\mathrm{Ca}, \mathrm{Sr})_{2} \mathrm{CuO}_{3}$, $\left.(\mathrm{Sr}, \mathrm{Ca})_{14} \mathrm{Cu}_{24}\right) \mathrm{O}_{41}$, and $(\mathrm{Bi}, \mathrm{Pb})_{3}(\mathrm{Sr}, \mathrm{Ca})_{4} \mathrm{Cu}_{1} \mathrm{O}_{\mathrm{y}}$. Overpressure processing has significantly reduced the amount of porosity in the sample shown in Fig. 2(a).

\section{B. Magnetic Behavior of Fully Processed Tape}

The shell of singly-connected colonies that line the interface region is sufficient to shield the interior regions of the filaments during magnetization measurements. As shown in Fig. 3, a 30\% reduction was used to break up the connectivity in the tape and reveal the discontinuity in the $\boldsymbol{m}$ vs. T curves that is associated with the presence of $\mathrm{Bi}-2212$ [11]. With the rolling step there is an overall reduction in the magnetization from 6 to $110 \mathrm{~K}$. In addition, the smaller signal in the temperature range of $\approx 60$ to $110 \mathrm{~K}$ in the $m$ vs. T curve is due to the $\mathrm{Bi}-2212$ that is now in the shielding pathway.

The connectivity of the shell is also seen in the optical micrograph, MOI, and current reconstruction map of Fig. 4. The darkest regions of Fig. 4(c) represent the highest $\mathrm{J}_{\mathrm{c}}$ regions of the tape, some of which are as high as $200 \mathrm{kA} / \mathrm{cm}^{2}$ at $77 \mathrm{~K}$ in this particular tape. The current reconstruction also shows a variable capacity for current transport across the core as indicated by the linear regions of high- $\mathrm{J}_{\mathrm{c}}$ material. 


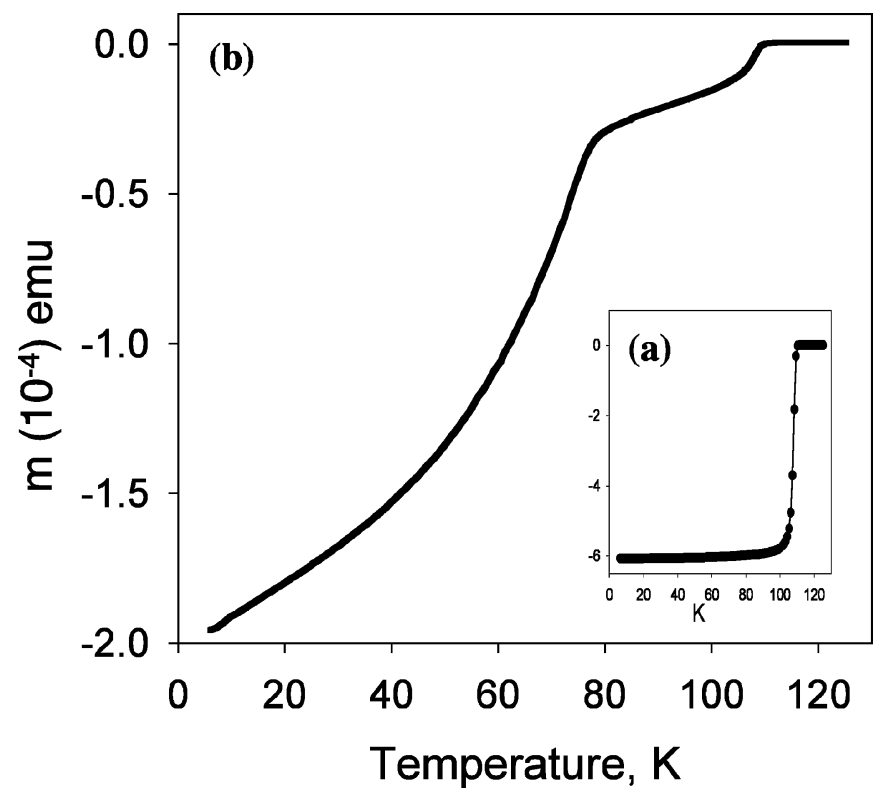

Fig. 3. Magnetic moment curves of (a) an as-processed mono-core tape that had a $J_{c}=35 \mathrm{kA} / \mathrm{cm}^{2}$ (self-field, $77 \mathrm{~K}$ ) and (b) the same tape after a $30 \%$ rolling reduction to break up the shell and inner region of the tape.



Fig. 4. Optical (a), MOI (b), and current reconstruction map (c) of a monocore tape with a $\mathrm{J}_{\mathrm{c}}$ of $41 \mathrm{kA} / \mathrm{cm}^{2}(77 \mathrm{~K}, \mathrm{sf})$.

\section{Intergrowth Structures in Fully Processed Tape}

Fig. 5 is a backscattered SEM image from one of the $200 \mathrm{kA} / \mathrm{cm}^{2}$ regions (from current reconstruction) of the tape shown in Fig. 4. It clearly shows that a large number of Bi-2212 grains and intergrowth/intergrowth structures are still present. Multiple TEM images have confirmed the arrangement of the residual $\mathrm{Bi}-2212$ as individual intergrowths, intergrowth structures, or as separate grains within the overall Bi-2223 colony structures.

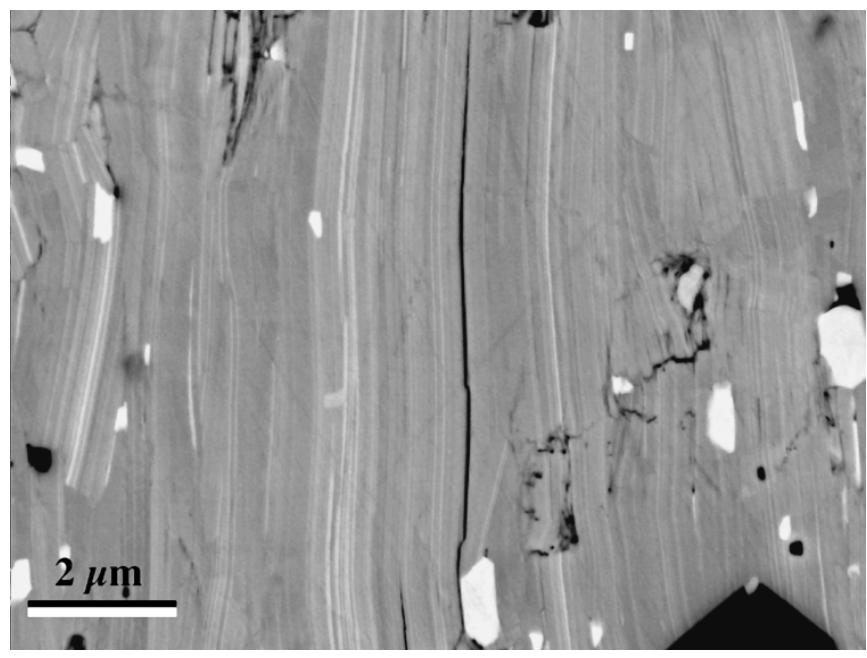

Fig. 5. SEM backscattered image from a monocore Bi-2223 tape cross-section where the local $\mathrm{J}_{\mathrm{c}}(77 \mathrm{~K})$ was determined to be $200 \mathrm{kA} / \mathrm{cm}^{2}$ by MOI and current reconstruction. The overall $\mathrm{J}_{\mathrm{c}}$ (self-field, $77 \mathrm{~K}$ ) was $41 \mathrm{kA} / \mathrm{cm}^{2}$. The bright streaks are layers/intergrowths of Bi-2212.

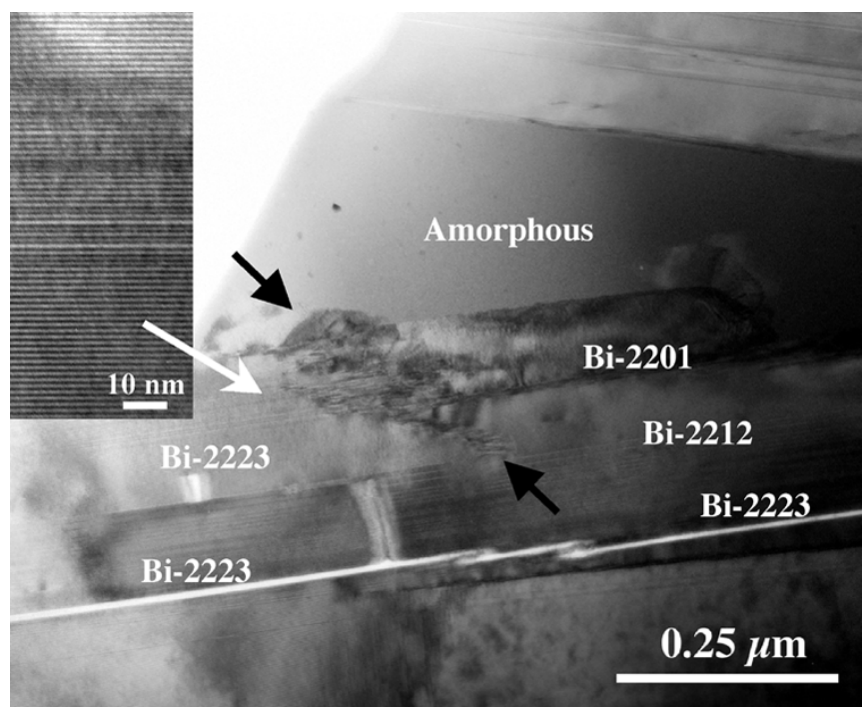

Fig. 6. TEM image (a) of a Bi-2223 multifilamentary tape quenched after $500 \mathrm{~min}$ into the first heat treatment that shows the precipitation of the Bi-2223 phase from an intermediate liquid phase. The inset (b) shows the Bi-2212 intergrowth structures that can be found in the Bi-2223 grains at this stage of the process.

\section{Initial Stages of Bi-2223 Phase Formation}

Fig. 6 is a TEM image of a Bi-2223 multifilamentary tape that was quenched after 500 minutes at $827^{\circ} \mathrm{C}$ during its first heat treatment. The precipitation of the $\mathrm{Bi}-2223$ phase from the liquid is a nonuniform event where multiple intergrowths or layers of $\mathrm{Bi}-2212$ co-precipitate with the $\mathrm{Bi}-2223$. A composition of $\mathrm{Bi}_{1.24} \mathrm{~Pb}_{0.92} \mathrm{Sr}_{0.70} \mathrm{Ca}_{0.44} \mathrm{Cu}_{1.70} \mathrm{O}_{\mathrm{y}}$ was measured for the liquid phase in a number of samples quenched between 1 and 300 minutes into the initial heat treatment. The composition of the liquid phase was found to be relatively constant over this interval. 


\section{DisCUSSION}

The present form of oxide-powder-in-tube (OPIT) processing for Bi-2223 tapes results in a filament structure that can be described in terms of a shell and core. The shell appears to singlyconnected $\mathrm{Bi}-2223$ colonies that are grapho-epitaxially aligned ( $c$ axis perpendicular to the interface) to the silver sheath. There are very few secondary phases or Bi-2212 intergrowths in this shell region. It is only when this shell is broken by mechanical deformation that one can detect the residual Bi-2212 by D.C. magnetization experiments.

The core of the filaments is where most of the residual secondary phases, including Bi-2212, and porosity arelocated. Thisistruefor both monocore or multifilament tapes. In this region, many of the $\mathrm{Bi}$-2223 grains are misaligned relative to the silverinterface. Overpressure processing has been shown tobeeffectiveforreducing the porosity in the core [15]. Changes in the phase assemblage and/or reductions in the secondary phase content have been obtained with variations in the heat treatments [2], [11], [16], [17]. However, the best $\mathrm{Bi}-2223$ tapes that are currently produced still have greater than 10 vol.\% residual secondary phases, which includes Bi-2212 grains and intergrowth structures [11].

Prolonged anneals suggest that the features described above, especially the $\mathrm{Bi}-2212$ grains and intergrowth structures, are relatively stable [18]. It appears that the overall structure (shell and core) and the phase content (conversion efficiency, secondary phases, porosity, Bi-2212 intergrowth structures) are largely determined in the initial stages of conversion. Perturbations to the heat treatment such as variable oxygen partial pressures, thermal slide heat treatments, or overpressure processing can change the relative phase assemblage, but not the overall structure [2], [16], [17]. To change the overall structure, it appears that substantial changes would have to be made in the initial stages of the tape manufacture and initial heat treatment.

\section{SUMMARY}

The filament structure in Bi-2223 monocore and multifilamentary tapes was shown to be composed of a shell and core. The shell is a connection of $\mathrm{Bi}-2223$ colonies that are grapho-epitaxially aligned to the silver interface. This single layer of Bi-2223 colonies is only interrupted by defects or discontinuities along the $\mathrm{BSCCO} /$ silver interface. The interior region or core contains most of the secondary phases and porosity. Only the Bi-2223 grains next to the silver interface were found to be free of $\mathrm{Bi}-2212$ intergrowths. This filament structure forms during the early stages of heat treatment and is stable against perturbations introduced during subsequent thermo-mechanical heat treatments.

\section{REFERENCES}

[1] L. Masur, D. Parker, M. Tanner, E. Podtburg, D. Buczek, J. Scudiere, P. Caracino, S. Spreafico, P. Corsaro, and M. Nassi, "Long length manufacturing of high performance BSCCO-2223 tape for the Detroit Edison power cable project," IEEE Trans. Appl. Supercond., vol. 11, pp. 3256-3260, 2001.
[2] Y. Yuan, J. Jiang, X. Y. Cai, D. C. Larbalestier, E. E. Hellstrom, Y. Huang, and R. D. Parrella, "Significantly enhanced critical current density in $\mathrm{Ag}$-sheathed $(\mathrm{Bi}, \mathrm{Pb})_{2} \mathrm{Sr}_{2} \mathrm{Ca}_{2} \mathrm{Cu}_{3} \mathrm{O}_{\mathrm{x}}$ composite conductors prepared by overpressure processing in final heat treatment," Appl. Physics Lett., vol. 84, pp. 2127-2129, 2004.

[3] S. Patanik, D. M. Feldmann, A. A. Polyanskii, Y. Yuan, J. Jiang, X. Y. Cai, E. E. Hellstrom, D. C. Larbalestier, and Y. Huang, "Local measurement of current density by magneto-optical reconstruction in normally and overpressure processed Bi-2223 tapes," IEEE Trans. Appl. Supercond., vol. 13, pp. 2930-2933, 2003.

[4] Y. Hakuraku and Z. Mori, "Rapid annealing effect in the superconducting $2223 \mathrm{Bi}(\mathrm{Pb}) \mathrm{SrCaCuO}$ thin films prepared by sputtering," $J$. Appl. Phys., vol. 73, pp. 309-315, 1993.

[5] O. Eibl, "The high- $\mathrm{T}_{\mathrm{C}}$ compound $(\mathrm{Bi}, \mathrm{Pb})_{2} \mathrm{Sr}_{2} \mathrm{Ca}_{2} \mathrm{Cu}_{3} \mathrm{O}_{10+\partial}$ : features of the structure and microstructure relevant for devices in magnet and energy technology," Supercond. Sci. Technol., vol. 8, pp. 833-861, 1995.

[6] T. G. Holesinger, J. F. Bingert, J. O. Willis, Q. Li, R. D. Parrella, M. D. Teplitsky, M. W. Rupich, and G. N. Riley, Jr., "Structural and compositional defects in high- $\mathrm{J}_{\mathrm{C}}$ Bi-2223 tapes," IEEE Trans. Appl. Supercond., vol. 9, pp. 2440-2446, 1999.

[7] T. G. Holesinger, J. F. Bingert, R. D. Parrella, and G. N. Riley, Jr., "The development of the superconducting phase and the origin of potential current limiting defects in Bi-2223 tapes," in Int. Cryogenic Mater Conf.-ICMC, vol. 48, Advances in Cryogenic Engineering-Materials, B. Balachandran, D. Gubser, and K. Hartwig, Eds., Madison, Wisconsin, 2002, pp. 724-731. American Institute of Physics.

[8] T. G. Holesinger, J. F. Bingert, M. Teplitsky, Q. Li, R. D. Parrella, M. P. Rupich, and G. N. Riley, Jr., "Spatial variations in composition in high-J c Bi-2223 tapes," J. Mater. Res., vol. 15, pp. 285-295, 2000.

[9] X. Y. Cai, A. Polyanskii, Q. Li, G. N. Riley, and D. C. Larbalestier, "Current-limiting mechanisms in individual filaments extracted from superconducting tapes," Nature, vol. 392, pp. 906-909, 1998.

[10] J. Jiang, X. Y. Cai, J. G. Chandler, S. Patanik, A. A. Polyanskii, Y. Yuan, E. E. Hellstrom, and D. C. Larbalestier, "Critical current limiting factors in post annealed $(\mathrm{Bi}, \mathrm{Pb})_{2} \mathrm{Sr}_{2} \mathrm{Ca}_{2} \mathrm{Cu}_{3} \mathrm{O}_{\mathrm{x}}$ tapes," IEEE Trans. Appl. Supercond., vol. 13, pp. 3018-3021, 2003.

[11] Y. B. Huang, X. Y. Cai, G. N. Riley, Jr., D. C. Larbalestier, D. Yu, M. Teplitsky, A. Otto, S. Fleshler, and R. D. Parrella, "Progress in Bi-2223 tape performance," in Int. Cryogenic Mater. Conf-_ICMC, vol. 48 , Advances in Cryogenic Engineering-Materials, B. Balachandran, D. Gubser, and K. Hartwig, Eds., Madison, Wisconsin, 2002, pp. 717-723. American Institute of Physics.

[12] J. W. Anderson, X. Y. Cai, D. M. Feldmann, A. A. Polyanskii, J. Jiang, J. A. Parrell, K. R. Marken, S. Hong, and D. C. Larbalestier, "The influence of intermediate roll characteristics on the residual crack density and critical current density in multifilamentary $(\mathrm{Bi}, \mathrm{Pb})_{2} \mathrm{Sr}_{2} \mathrm{Ca}_{2} \mathrm{Cu}_{3} \mathrm{O}_{\mathrm{x}}$ tapes," Supercond. Sci. Technol., vol. 12, pp. 617-623, 1999.

[13] J. W. Anderson, S. E. Dorris, J. A. Parrell, and D. C. Larbalestier, "The effect of lead content on the critical current density, irreversibility field, and microstructure of $\mathrm{Ag}$-clad $\mathrm{Bi}_{1.8} \mathrm{~Pb}_{\mathrm{x}} \mathrm{Sr}_{2} \mathrm{Ca}_{2} \mathrm{Cu}_{3} \mathrm{O}_{\mathrm{y}}$ tapes," $J$. Mater. Res., vol. 14, pp. 340-348, 1998.

[14] D. M. Pooke, M. R. Presland, O. R. Mercier, Y. B. Huang, Q. Li, and A Otto, "Texture analysis in the thermo-mechanical processing of Bi-2223 tapes," IEEE Trans. Appl. Supercond., vol. 13, pp. 2984-2987, 2003.

[15] Y. Yuan, J. Jiang, X. Y. Cai, S. Patanik, A. A. Polyanskii, E. E. Hellstrom, D. C. Larbalestier, R. K. Williams, and H. Y., "Microstructure and Jc improvements in overpressure processed Ag-sheathed Bi-2223 tapes," IEEE Trans. Appl. Supercond., vol. 13, pp. 2921-2925, 2003.

[16] T. G. Holesinger, J. F. Bingert, J. O. Willis, V. A. Maroni, A. K. Fischer, and K. T. Wu, "The effects of variable oxygen partial pressures during Bi-2223 tape processing," J. Mater. Res., vol. 12, pp. 3046-3054, 1997.

[17] Y. L. Tang, D. J. Miller, R. M. Baurceanu, V. A. Maroni, and R. D Parrella, "Improved microstructure in Ag/Bi-2223 composite tapes by systematic variation of heat treatment parameters," Supercond. Sci. Technol., vol. 15, pp. 1365-1371, 2002.

[18] J. Jiang and E. E. Hellstrom, private communication, 2004 Univ. Wisconsin, Madison WI, Private Communication. 